\title{
UMA EXPERIÊNCIA DE EDUCAÇÃO SEXUAL NA PRÉ-ESCOLA
}

Débora Dalbosco Dell'Aglio'

Aida Cássia Leal Garcia ${ }^{2}$

\section{Resumo}

Este trabalho relata a experiência de educação sexual que vem sendo desenvolvida na Creche Francesca Zacaro Faraco, da Universidade Federal do Rio Grande do Sul, nos últimos cinco anos. É um trabalho que tem envolvido as professoras, técnicos dos setores de Psicologia e Pedagogia, pais e alunos das turmas de Jardins (crianças entre 5 e 6 anos), ocorrendo, portanto, de forma integrada entre a Escola Infantil e as famílias. São apresentados alguns conceitos teóricos que embasam o trabalho, a forma como foi sistematizado o projeto pedagógico de educação sexual e as repercussões na comunidade envolvida.

O processo de Educação sexual, conforme Suplicy (1990), é um processo que ocorre durante toda a vida do indivíduo, desde o seu nascimento, e dele fazem parte todas as pessoas que convivem com a criança: pais, parentes, professoras, empregadas, e inclusive a mídia. Por isso a discussão sobre sexo precisa e deve ser encaminhada como parte da vida, assim como todas as outras descobertas e assuntos trazidos pelas crianças, e tratada com continuidade, embora existam fases diferentes e ritmos próprios que precisam ser respeitados.

Calderone e Ramey (1986) afirmam que as bases da Educação Sexual da criança iniciam quando ela recebe atendimento para suas necessidades de alimento e afeto. Assim, cuidar da alimentação, acariciar, segurar e trocar a criança com cuidado e atenção poderão lhe dar sentido da confiança, que servirá de base para bons sentimentos. A capacidade para a intimidade e a confiança estabelecida na infância repercutirá na capacidade de intimidade e confiança em uma relação amorosa, anos depois.

Chagas (1995) considera que é mister educar para a sexualidade, não de forma não-verbal, intuitiva e assistemática como fazemos, mas de forma intencional e sistemática, para que possamos desfrutar de nossa sexualidade e respeitar a sexualidade de outros. Na infância, para Suplicy (1990), a

1- Psicóloga e Doutoranda em Psicologia do Desenvolvimento pela UFRGS. (Instituto de Psicologia, UFRGS, Ramiro Barcelos, n²600, Porto Alegre - 90035-003, Brasil).

2- Pedagoga Pré-Escolar e Orientadora Educacional. 
orientação sexual não é feita de forma sistematizada porque a criança fala sobre suas dúvidas a qualquer hora. Afirma, ainda, que o tema deverá ser abordado sempre que aparecerem situações com conotação sexual ou que possam ser usadas para esclarecimentos, e que, o professor deve estar atento para tomar a iniciativa quando a oportunidade aparecer.

Uma criança que recebe orientação sexual, conforme Suplicy (1990), e que tem pais com quem possa conversar, tem maior possibilidade de assimilar os conceitos de responsabilidade pela própria saúde, higiene e bemestar. Além disso, a educação sexual dada pelos pais implica não somente em passar informações e transmitir valores, mas também em desenvolver o respeito pelo outro. Souza e Osório (1993) afirmam que cada criança é diferente da outra e que os pais é que as conhecem bem, sendo que a educação sexual da criança cabe, então, fundamentalmente a eles. Para tanto sugerem que os pais sejam chamados na escola, para dialogar sobre o assunto, receber esclarecimentos úteis e poder assim estar mais aptos a dar educação sexual aos seus filhos.

$\mathrm{Na}$ Escola Infantil também precisa haver espaço para que as crianças possam falar de questões sobre as quais têm dúvidas e curiosidade, questões sobre nascimento, diferenças sexuais e reprodução. Estes assuntos precisam ser conversados da mesma forma como se explica para a criança outras funções do seu corpo e fatos da sua vida. As perguntas como, por exemplo, "de onde eu vim?”, demonstram não só o interesse da criança pelo sexo, mas também revelam que ela está pensando, querendo entender onde ela começou. Quando a criança se dá conta das diferenças entre meninos e meninas quer saber que diferenças são essas, porque elas existem. A criança está assim, buscando sua história, sua origem e ao mesmo tempo exercitando sua inteligência. Para Chagas (1995), devem ser oferecidas oportunidades para a criança perguntar, manusear, observar, experimentar, satisfazer curiosidades e ser valorizada. A criança que percebe que sua curiosidade é boa, reforça a certeza de que está tudo bem com ela e também aprende a contar com os adultos para compartilhar dúvidas e sentimentos.

\section{A Educação Sexual na Pré-Escola}

O trabalho de educação sexual que vem sendo desenvolvido, na Escola Infantil da UFRGS, começou a partir do interesse em assuntos relacionados à questões sexuais, manifestado pelas crianças das turmas de jardins na nossa creche ( 5 e 6 anos). Os professores percebiam manifestações das crianças através de jogos sexuais, brincadeiras de namoro, tentativas de se espiarem no banheiro e de levantarem as saias das meninas, risadas frente a refe- 
rências à partes do corpo, entre outras. Inicialmente as professoras não sabiam como lidar com estas situações, que lhes traziam ansiedade, dúvidas e até mesmo constrangimento. Os próprios pais procuravam a creche, através das professoras e psicólogas, buscando orientação sobre como proceder com seus filhos e como falar sobre sexo com eles. Em alguns casos, em que foi percebido um comprometimento maior da criança ou da família, houve necessidade de encaminhamento para acompanhamento psicológico fora da instituição. A partir dessa demanda, a equipe técnica e professores da Instituição passaram a pensar em trabalhar estas questões de uma forma mais objetiva. Através de leituras, discussões em reuniões junto aos setores de Pedagogia e Psicologia, palestras sobre o assunto, foi visto que se poderia falar sobre sexo com as crianças, assim como eram falados outros temas. Foi percebido também que o tema sexo poderia não só ser falado, mas que também este era um tema que podia ser trabalhado de forma pedagógica e podia fazer parte das atividades diárias.

As primeiras tentativas de desenvolver este trabalho, junto às crianças, começaram a partir de conversas informais, nas quais era feita uma sondagem quanto às idéias, interesses e curiosidades do grupo. A partir desse levantamento foi vista a necessidade de procurar materiais adequados para trabalhar o assunto. Foram adquiridos livros infantis sobre o nascimento dos bebês, atlas do corpo humano, bonequinhos de pano com sexo, a boneca grávi$\mathrm{da}$, procurando assim proporcionar às crianças material lúdico que pudesse ser manuseado por elas.

Passaram a ser realizadas reuniões, junto a professores e técnicos dos setores de Psicologia e Pedagogia, nas quais eram discutidas as manifestações das crianças observadas em sala de aula e pátio, os manejos utilizados e as formas que estes aspectos poderiam ser trabalhados. Nestas reuniões também eram discutidas atividades pedagógicas para serem desenvolvidas em sala de aula, com o objetivo de trabalhar as questões sexuais de uma forma lúdica e descontraída. Foram então desenvolvidos jogos pedagógicos especialmente para trabalhar a questão da gravidez, do nascimento do bebê, crescimento e diferenças entre meninos e meninas. Estes jogos envolviam estes temas e ao mesmo tempo trabalhavam a questão lógico-matemática, o respeito às regras, a escrita e a expressão através do desenho nos relatórios realizados pelas crianças após os jogos. Este material foi muito bem aceito pelas crianças, que passaram a manuseá-los com interesse e naturalidade.

Foram também realizados seminários teóricos com o objetivo de estudar as fases do desenvolvimento e as fantasias sexuais infantis, tomando como referência a teoria psicanalítica (Rappaport, Fiori \& Davis, 1981; Kupfer, 
1992), e estudos sobre a educação sexual para crianças, com base na leitura do livro "Papai, Mamãe e Eu", de Suplicy (1990). Estes estudos foram importantes porque o conhecimento teórico possibilitou aos professores um maior entendimento do que ocorria com seu grupo, de acordo com as diferentes faixas etárias atendidas, permitindo também um manejo mais adequado de situações diárias.

O trabalho foi realizado de forma integrada aos pais das crianças. Para isso, as atividades a serem desenvolvidas foram comunicadas previamente, através de uma comunicação por escrito, com a indicação de bibliografia a ser consultada e com sugestões de livros para serem lidos junto às crianças (Anexo 1). Foram realizadas reuniões onde também eram apresentadas questões teóricas e práticas, relacionadas à educação sexual e ao desenvolvimento infantil. Nestas reuniões era enfatizada a importância da participação dos pais na orientação sexual de seus filhos, mostrando também o quanto a família ganha em termos de confiança e proximidade afetiva com esse aprendizado. Também era apresentado o procedimento da escola em relação ao trabalho de educação sexual e seus objetivos, deixando claro que a função da escola é de informar, trabalhando com respeito à criança, procurando orientar e responder as perguntas com informações corretas e científicas, desmistificando concepções equivocadas e trabalhando de acordo com o interesse manifestado pelo grupo. Era deixado claro que cabe à família a formação integral, que inclui o desenvolvimento de valores morais e afetivos, e que por isso o trabalho precisava ser desenvolvido em conjunto. Em alguns casos houve necessidade de entrevistas individuais com os pais que procuravam a orientação do Setor de Psicologia ou a pedido das professoras em casos especiais.

Os pais também passaram a participar do trabalho na medida em que as professoras solicitavam às crianças que fizessem perguntas em casa sobre a origem do seu nome, sobre como foi seu nascimento, como os pais se conheceram, e também solicitando fotos da mãe grávida e do bebê. Os pais passaram a participar das atividades com entusiasmo; escrevendo, de forma muito afetiva, o que os levou a escolher o nome de seu filho; trazendo ecografia da gravidez em foto e até mesmo em fita; trazendo roupinhas de quando seus filhos eram pequenos. Assim foi visto o quanto estava sendo importante incluílos no trabalho e foi percebida, pelos professores, uma maior aproximação entre pais e filhos através destas atividades. Por diversas vezes, os pais eram encontrados na entrada ou nos corredores da instituição, contando para outros pais ou professores as novas descobertas das crianças. Pais de turmas onde o trabalho não estava sendo realizado, passaram a procurar as professores e os técnicos dos setores, solicitando-lhes que também desenvolvessem o trabalho 
na turma de seu filho.

As crianças se envolviam de forma muito afetiva com as atividades. Foram realizados painéis com as fotos das crianças quando eram bebês e as próprias professoras trouxeram suas fotos. Isso surpreendeu as crianças que se admiraram ao ver que suas professoras também haviam sido crianças.

Durante este trabalho, também houve necessidade de trabalhar limites. Foram realizadas conversas e discussões em "rodinha", sobre as diferenças entre o que os adultos podem fazer e o que as crianças podem fazer, assim como sobre a diferença do namoro de adultos e de crianças. Isso foi necessário como uma forma de dar um limite ao grupo, quanto ao que poderia ser feito ou não, já que eram observadas situações de constrangimento por parte de algumas crianças junto à outras, através de brincadeiras como tirar a roupa ou beijar mesmo que o colega não quisesse. Além disso, através dos relatos dos pais ou das próprias crianças, era percebido que elas assistiam muita TV em casa, sendo expostas a filmes, novelas e propagandas relacionadas a sexo. Sabe-se, no entanto, que estes assuntos geralmente não são conversados, dentro da família, em função da repressão existente na nossa cultura e porque existe uma idéia, não explícita entre as pessoas, de que a "ingenuidade" das crianças precisa ser preservada. Mas estas questões, não conversadas, eram trazidas pelas crianças para a creche, através de perguntas e jogos simbólicos com imitação dos personagens e suas atitudes, demonstrando em suas brincadeiras diárias uma grande dificuldade de perceber o que seria adequado numa relação entre crianças e entre adultos. Tendo em vista que a maioria das crianças passa o dia todo na creche, a instituição não poderia deixar de ocupar este espaço para trabalhar a educação sexual e os limites implicados. Assim, foi preciso salientar a questão do respeito que cada um deve ter por outra pessoa e trabalhar noções de limite entre o eu e o outro. Com a verbalização destas questões, além das demais atividades desenvolvidas, pode ser percebida uma redução na ansiedade manifestada pelas crianças em relação às questões sexuais, que passaram a ser tratadas com mais espontaneidade.

No início houve necessidade de um acompanhamento mais específico do Setor de Psicologia junto às professoras, com o objetivo de trabalhar os sentimentos despertados, pois a questão sexual, principalmente junto às crianças nesta faixa etária, mobiliza ansiedades no adulto que está desenvolvendo o trabalho. Havia um temor inicial, por parte das professoras, de que o trabalho de educação sexual pudesse aumentar mais a ansiedade e a agitação das crianças, e também um receio quanto à receptividade do trabalho por parte dos pais. Em alguns casos houve orientação individual à professora pelo Setor de

Paidéia FFCLRP-USP, Rib.Preto, fev/ago 97. 
Psicologia, para que elas pudessem estar conscientes de suas próprias dificuldades de modo que estas não prejudicassem o seu trabalho e a sua relação com o grupo de crianças. Foi visto que as professoras é que deveriam desenvolver a atividade de educação sexual, considerando a importância do vínculo existente com as crianças e que este tema não poderia ser tratado de forma diferenciada dos outros temas trabalhados na pré-escola, pois conforme Chagas (1995), a presença de adultos afetivos e preparados para encarar com naturalidade e conhecimento as manifestações sexuais da criança é fundamental e contribuirá para humanizá-la mais. Dessa forma, as professoras passaram a se sentir mais seguras em desenvolver estas atividades, percebendo com mais clareza seus objetivos.

A partir do retorno percebido, por parte das crianças e dos pais, a educação sexual na pré-escola passou a ser desenvolvida nos anos seguintes, sendo que a cada experiência novas contribuições e idéias são acrescentadas, aperfeiçoando cada vez mais o trabalho.

\section{Um Projeto Pedagógico}

Aos poucos o trabalho passou a ser realizado de uma forma mais sistemática, constituindo-se também num projeto pedagógico. Este projeto, no entanto, tem tido um caráter permanente, na medida em que o processo de educação sexual ocorre durante toda a vida, e as crianças não tem um tempo específico para tratar do assunto. Então, mesmo nas turmas onde o projeto já tenha sido desenvolvido, as questões relativas à educação sexual podem ser retomadas sempre que necessário, ou seja, sempre que for percebido, por parte das professoras, comportamentos ou verbalizações das crianças indicando a necessidade de conversar sobre $o$ assunto.

O projeto de educação sexual, assim como os demais projetos trabalhados na pré-escola, tem sido realizado de acordo com a proposta pedagógica da instituição, embasada na teoria epistemológica de Piaget ( Flavel, 1975; Kamii \& Devries, 1980, 1991; Piaget, 1975a, 1975b,1977, 1978; Piaget \& Inhelder, 1985). Considerando a proposta pedagógica de educação construtivista, as atividades são desenvolvidas de forma a estimular a aquisição de autonomia afetiva e intelectual pela criança, capacidade de descentração, coordenação de diferentes pontos de vista e atitudes de cooperação no grupo. Assim as atividades são realizadas de forma flexível, de acordo com as características e o interesse manifestado pelas crianças, sendo que elas também participam de forma ativa da escolha das atividades e da forma de desenvolvê-las. Além disso, o projeto engloba os diversos conhecimentos a serem trabalhados nesta faixa etária, como a aprendizagem da lecto-escrita, atividades que envolvem o 
raciocínio lógico-matemático, ciências, conhecimentos gerais e outros, constituindo-se num projeto interdisciplinar.

Como um projeto pedagógico, o projeto de educação sexual passou a incluir diversas atividades que podem seguir o seguinte roteiro:

1. Noção de sexo:

- Desenvolver conversas informais sobre o que é ser menino, o que é ser menina.

- Realizar atividades de recorte, colagem, pintura de figuras masculinas e femininas.

- Conhecer pertences masculinos e femininos: fazer cartazes com equipes.

- Discutir sobre o papel do vestuário: proteger ou esconder.

- Discutir diferenças e semelhanças entre roupas femininas e roupas masculinas, roupas comuns.

- Realizar jogos que envolvem a compra e colagem de peças do vestuário.

- Estudar o vestuário através dos tempos (homens que usavam saias antigamente).

- Jogo lúdico: uso de fantasias, dramatizações dos diferentes papéis.

- Observar a troca de fraldas em bebês do berçário e repetir a experiência com bonecos.

- Listar brincadeiras que os meninos gostam mais, que as meninas gostam mais e brincadeiras comuns.

- Pesquisar nomes de meninos e meninas: diferenças e origem dos nomes.

- Pesquisa junto aos pais sobre a origem do próprio nome.

- Explorar a transformação de nomes masculinos em femininos e vice-versa ( com letras móveis).

\section{O Corpo:}

- Desenvolver conversas informais sobre partes do corpo.

- Desenhar moldes do contorno do corpo em papel pardo e completá-los com desenho ou com colagem ( usando botões, lã, pedaços de tecido, etc...). 
- Nomear as partes do corpo utilizando vocabulário adequado.

- Confeccionar com as crianças quebra-cabeças de meninos e meninas, da família, comparando tamanhos e diferenças.

- Estimular atividades na frente do espelho.

- Modelar bonecos com sexo com massinha ou argila.

\section{Higiene:}

- Desenvolver conversas informais sobre hábitos de higiene (como a criança toma banho, como se limpa no banheiro).

- Banhar bonecos (tirar a roupa de bonecos com sexo).

4. De onde eu vim?

- Realizar uma sondagem com o grupo, registrando as idéias iniciais de cada um.

- Ler para as crianças livros de orientação sexual sugeridos (relacionados no Anexo 1).

- Comparar o homem com outros seres vivos: as plantas nascem de sementes, alguns animais nascem de ovos e outros nascem da "barriga".

- Entrevistar uma gestante (dive ser preparada de acordo com o objetivo da atividade): as crianças podem tocar a barriga e fazer perguntas.

- Examinar roupinhas de bebê e fotos da mamãe grávida e do bebê recém-nascido.

- Confecção de painéis com as fotos das crianças quando eram bebês.

- Desenvolver atividades de recorte e colagem: figuras de gestantes, de bebê e mamãe.

- Desenhar-se no útero da mãe.

\section{Como eu saí?}

- Conversar sobre o parto, a diferença entre parto normal e cesária (nem sempre a mamãe corta a barriga). médico e bebê.

- Realizar dramatizações de parto normal e cesária: pai, mãe,

- Realizar brincadeiras com a boneca grávida.

- Desenhar o seu nascimento: antes as crianças pesquisam em 
casa como foi que nasceu.

\section{Como eu entrei?}

sentadas.

- Realizar uma sondagem com o grupo: registrar as idéias apre-

- Explicar de forma simples e objetiva como se dá a concepção, utilizando livros e termos adequados: "as mulheres tem um canalzinho para fazer os bebês. $O$ papai coloca os espermatozóides neste canalzinho que se chama vagina".

- Possibilitar às crianças o manuseio de livros com gravuras.

- Realizar o jogo de seqüência dos nove meses de gestação: um jogo que utiliza uma trilha com o desenho de uma gestante em que o tamanho do útero vai aumentando. As crianças precisam completá-la, colocando os fetos em ordem crescente de tamanho e numerando cada etapa do 1 ao 9 .

- Visita a museu para observar o corpo humano e fetos.

- Observação de fetos em formol.

- Construir um texto coletivo com o grupo sobre o que aprendeu sobre a concepção e nascimento.

\section{A Família:}

- Conversar sobre como se forma a família: o que são tios, avós, primos, etc..., os diferentes tipos de família.

- Pesquisar como se formou a sua família: como os pais se conheceram.

- Realizar dramatizações sobre os papéis da família.

- Listar direitos e deveres dos membros da família: pais, filhos, avós.

- Discutir sobre as diferenças entre o que os adultos podem fazer e o que as crianças podem fazer.

- Conversar sobre a diferença do namoro de adultos e de crianças.

O projeto tem sempre iniciado com um registro das idéias espontâneas das crianças, que serve como um tipo de sondagem do grupo. Através destas idéias pode-se perceber as fantasias das crianças sobre a concepção e nascimento, como nas seguintes verbalizações: "o bebê sobe pela barriga da 
mãe, pelos canos que ela tem dentro"; "a mãe vai para o hospital e o papai do céu vem e dá o nenê"; "eu não vi mas acho que a maninha entrou sozinha na barriga da mãe"; "ele é bem pequenininho, entra pela boca e vai para a barriga dentro do sangue"; "o bebê faz um furo para entrar na barriga da mãe e para sair também. O médico costura o furo"; "ele vem na comida que a mãe come. Ela cuida para não morder"; "cortam a barriga da mãe e colocam o bebê lá dentro"; "os pais se casam e o nenê já está na barriga"; "o bebê vem do céu".

As professoras são orientadas no sentido de introduzir os assuntos nas conversas informais com as crianças de acordo com o interesse apresentado por elas, sempre utilizando livros infantis que ilustrem o tema estudado. Durante o desenvolvimento do projeto as professoras fazem um registro diário das hipóteses e avanços das crianças através do desenho e escrita. As crianças são estimuladas a exercitarem a escrita espontânea das palavras trabalhadas durante as atividades realizadas. $O$ acesso ao material didático é facilitado e as perguntas feitas devem sempre ser respondidas, de forma clara e objetiva, corrigindo distorções, quando for o caso.

As palavras utilizadas pelas crianças para nomear partes do corpo, e que são usadas no âmbito de cada família, são aceitas pelas professoras, que no entanto introduzem os termos adequados, associando-os com os termos conhecidos pelas crianças. É necessário descobrir junto à elas, o significado das palavras, que às vezes são utilizadas de forma inadequada, esclarecendo, organizando as informações, corrigindo-as, enriquecendo-as e mostrando à criança que sempre que quiser poderá contar com a ajuda do educador.

O fechamento do projeto pedagógico tem sido a construção de um texto coletivo, que se constitui num relato sobre tudo o que o grupo aprendeu sobre a concepção e nascimento. A partir da construção deste texto, é montado um livro, no qual cada página tem algumas frases do texto coletivo e é ilustrada pelas próprias crianças. É confeccionada uma capa onde consta o título do livro, escolhido pelo grupo, e o nome dos autores onde cada criança assina seu nome. Assim as crianças se sentem importantes, pois lhes é atribuída a autoria de um texto, e isso lhes dá mais liberdade para se apropriarem do conteúdo trabalhado.

Através da observação dos "livros" construídos pelas crianças, nestes cinco anos em que tem sido desenvolvido este trabalho, pode-se observar que elas apresentam, em seus textos coletivos, idéias claras sobre a concepção, gravidez e nascimento, sem as distorções verificadas antes do projeto. Isto pode ser evidenciado nas seguintes verbalizações das crianças: "para fazer o nenê precisa da coisa do papai que se junta com a coisa da ma- 
mãe"; "o espermatozóide vai nadando igual a um peixinho para o óvulo. Ele entra no óvulo e começa a nascer o nenê, começa pequeno e vai crescendo"; "quando a mamãe dorme, o bebê também dorme e ele se alimenta do cordão umbilical porque ainda não pode tomar Nescau"; "ele come tudo que a mãe come pelo cordão umbilical"; "lá é escurinho e tem água quente que não deixa o bebê se bater"; "a mamãe grávida não pode fumar, nem beber vinho, nem cachaça Velho Barreiro. Tem que tomar suco e comer bastante fruta"; "perto da hora de nascer o nenê vira de cabeça para baixo e sai pela xerereca. Às vezes tem que cortar a barriga"; "o médico corta o cordão umbilical porque o bebê já pode se alimentar pela boca, pode mamar o leite da mamäe", entre outras.

\section{As Repercussões na Comunidade}

Com a realização deste trabalho professores e técnicos da instituição passaram a ver a educação sexual como mais um objetivo de trabalho junto às crianças, fazendo parte de uma proposta de educação e formação integral, e têm incluído a educação sexual nas atividades desenvolvidas na pré-escola. As professoras, na medida em que se sentiram mais seguras para tratar do assunto, puderam se aproximar mais das crianças e ampliar as possibilidades de atividades a serem desenvolvidas, passando a desenvolver o projeto de forma mais efetiva. Os pais aprovaram o trabalho, manifestando muito interesse e até mesmo se aproximando mais dos próprios filhos e da Escola.

As crianças, após este trabalho, passaram a conversar sobre diferenças entre meninos e meninas, gravidez e nascimento de uma forma menos carregada de ansiedade e mais cercada pelo prazer da descoberta, evidenciando satisfação em poder tratar do tema junto aos colegas, professores e família. Isto foi percebido através de uma redução das manifestações apresentadas antes do desenvolvimento do projeto nas turmas, como por exemplo jogos sexuais, risadinhas maliciosas e tentativas de se espiarem e tirarem a roupa, embora este tipo de comportamento continue ainda sendo percebido pelas professoras, até mesmo porque faz parte do desenvolvimento nesta faixa etária. No entanto, pode ser constatado que as crianças passaram a falar mais sobre estas situações com maior naturalidade, e a usar o espaço da escola para buscar novos conhecimentos relacionados a sua origem e ao seu lugar no mundo.

Além disso, a possibilidade dada às crianças de participarem da escolha das atividades e da forma de desenvolvê-las, exercendo um papel de alguém que constrói, também foi importante pois contribuiu para que houvesse espaço para as crianças coordenarem pontos de vista diferentes, tivessem espaço para relacionar os novos conhecimentos aos já existentes, podendo exer-

Paidéia FFCLRP-USP, Rib.Preto, fev/ago 97. 
cer a descentração dos seus pontos de vista, tornar-se mais críticas, abertas e curiosas e desenvolver a sua autonomia.

Durante esta experiência, tem sido possível confirmar que a informação diminui a ansiedade e abre caminho para pensar a própria experiência, promovendo o crescimento e colaborando para um desenvolvimento integral. A possibilidade de poder tratar de questões sexuais na pré-escola, tem ajudado na elaboração e compreensão de conflitos e ansiedades, e tem colaborado inclusive para que as crianças participem de uma forma mais tranquiila das demais atividades realizadas.

Considerando ainda, que a informação é uma forma de proteger a criança e lhe dar segurança, colaborando para que ela passe pelas diferentes fases evolutivas de forma sadia, podemos concluir que a educação sexual tem sido desenvolvida como um trabalho de prevenção e promoção de saúde, a nível da comunidade envolvida na instituição, e que pode desde já contribuir para um futuro mais saudável para as crianças e suas famílias.

\section{Referências Bibliográficas:}

CALDERONE, M. S. \& RAMEY, J. W. (1986). Falando com seu filho sobre sexo. São Paulo: Summus.

CHAGAS, E. R. C. (1995). A Sexualidade e a Criança. Revista do Professor. Porto Alegre: 11 (42): 5-7, abr./jun.

FLAVEL, J. H. (1975). A Psicologia do Desenvolvimento de Jean Piaget São Paulo: Pioneira.

KAMII, C. \& DEVRIES, R. (1980). A Teoria de Piaget e a Educação Pré-Escolar. Lisboa: Sociocultur.

KAMII, C. \& DEVRIES, R. (1991).Jogos em Grupo na Educacão Infantil. São Paulo: Trajetória Cultural.

KUPFER, M. C. (1992). Freud e a Educação - O Mestre do Impossível. São Paulo: Scipione.

PIAGET, J. (1975a). A Formação do Símbolo na Criança. Rio de Janeiro: Zahar.

PIAGET, J. (1975b). A Gênese do Número na Criança. São Paulo: EPU.

PIAGET, J. (1977). O Julgamento Moral da Criança. São Paulo: Mestre Jou. 
PIAGET, J. (1978). Seis Estudos de Psicologia. Rio de Janeiro: Forense Universitária.

PIAGET, J. \& INHELDER, B. (1985). A Psicologia da Criança. São Paulo: DIFEL.

RAPPAPORT, C. R.; FIORI, W. R. \& DAVIS, C. (1981). Psicologia do Desenvolvimento-Volume 3. A Idade Pré-Escolar. São Paulo: EPU.

SOUZA, R.P. \& OSÓRIO, L.C. (1993). A Educação Sexual de Nossos Filhos-Uma Visão Contemporânea. Porto Alegre: Mercado Aberto.

SUPLICY, M. (1990). Papai, Mamãe e Eu. São Paulo: FTD.

\section{ANEXO 1}

São sugestões de histórias infantis ou livros, para as professoras e os pais lerem junto à criança:

ANDRADE, T. G. C. (1993). Tem Gente. São Paulo: Editora Scipione.

ANDRY, A. C. \& SCHEPP, S. (1992). De Onde Vêm os Bebês? Rio de Janeiro: Editora José Olímpio.

AUGUSTO, M. G.; COSTA, M. \& PALADINO, S. M. (1991). As Crianças Querem Saber... e Agora? São Paulo: Casa do Psicólogo.

COLE, B. (1997). Mamãe Botou um Ovo! São Paulo: Editora Ática.

DONEY, M. \& DONEY, M. (1991). Quem me Fez? São Paulo: Edições Paulinas.

KNIGHT, J. F. (1987). A Vida Começa Assim. São Paulo: Casa Publicadora Brasiliense.

MAYLE, P.; ROBINS, A. \& WALTER. P. (1994). De Onde Viemos. São Paulo: Círculo do Livro.

MINERS, L. \& YNE, P. (1994).Aninha e João. São Paulo: Editora Ática.

PORTO, C.(1995) Da Cabeça aos Pés. São Paulo: Editora Moderna.

RIBEIRO, M. (1991). Menino Brinca de Boneca? Conversando sobre o que é ser menino e menina, Rio de Janeiro: Salamandra.

SACHS, D. (1987). A Irmãzinha. São Paulo: Editora Cedibra.

SHANE, R. \& SHANE, H. (1987). O Novo Bebê. São Paulo: Editora Cedibra. Scipione.

THIS, B. \& MORAND, C. (1992). De Onde Venho. São Paulo: Editora 


\section{ABSTRACT}

This paper describes a program of sex education under development in the pre-school Creche Francesca Zacaro Faraco, UFRGS, during the last five years. This activity has involved pre-school teachers, personnel from the Psycology and Pedagogy departaments, parents and pre-school children, aged between 5 and 6 years, integrating families and the university. The theoretical concepts supporting the work, the organization of the pedagogical project on education, and the repercussion on the community are presented and discussed.

\section{Key Words}

Child, sex education, pedagogical project, pre-school

\section{Palavras-chave}

Criança, educação sexual, projeto pedagógico, pré-escola 